\title{
Footprints of climate in groundwater and precipitation
}

\author{
A. Liebminger, G. Haberhauer, W. Papesch, and G. Heiss \\ Biogenetics - Natural Resources, Austrian Research Centers Seibersdorf, A-2444 Seibersdorf, Austria \\ Received: 16 January 2006 - Published in Hydrol. Earth Syst. Sci. Discuss.: 8 March 2006 \\ Revised: 21 September 2006 - Accepted: 22 January 2007 - Published: 26 January 2007
}

\begin{abstract}
In the last decades, the ${ }^{18} \mathrm{O} /{ }^{16} \mathrm{O}$ signature of meteoric water became a key tracer intensively used both in hydrology and in paleoclimatology, based primarily on the correlation of the ${ }^{18} \mathrm{O} /{ }^{16} \mathrm{O}$ ratio in precipitation with temperature. This correlation with temperature is generally well understood as a result of Rayleigh processes of atmospheric vapour during the formation of precipitation. The resulting isotopic signals in precipitation are also transferred into the groundwater body since the isotopic composition of groundwater is determined by the precipitation infiltrating into the ground. However, the whole variability of the ${ }^{18} \mathrm{O} /{ }^{16} \mathrm{O}$ ratio especially in temporal data series of precipitation and groundwater can not be explained with temperature alone. Here we show that certain interactions between different climate induced changes in local parameters prevailing during precipitation events are able to explain a significant part of the observed deviation. These effects are superimposed by an overall isotopic pattern representing the large scale climate input primarily based on temperature. The intense variability of isotopes due to the particular topography of Austria recorded over a time period of 40 years provides an unique possibility to uncover this hidden information contributed by relative humidity and type of precipitation. Since there is a growing need to predict the variation of climate together with its associated potential hazards like floods and dry periods the results of this work are contributing to a better overall understanding of the complex interaction of climate with the corresponding water cycle.
\end{abstract}

\section{Introduction}

It is of common understanding that isotopic depletion in atmospheric waters is based conceptually on a Rayleigh distillation process (Dansgaard, 1964; Clark and Fritz, 1997) describing the fractionation that differentiates the heavy and light molecules as to be strongly dependent on temperature.

Correspondence to: A. Liebminger

(a.liebminger@tele2.at)
Although simple distillation models fail to consider the entire history of moisture that leads to the final isotopic content of precipitation it is found that there is indeed some correlation between the isotopic composition of precipitation and the local temperature (Siegenthaler and Oeschger, 1980), but at all timescales examined a large part of the variance in the isotope data remains unexplained. Typically only $20 \%$ of this isotope variance can be explained by temperature changes (Noone and Simmonds, 2002) and thus the accurate acquisition of paleotemperature from isotope data has been placed under scrutiny (Edwards and Wolfe, 1996; Jouzel et al., 1997).

Most of the research regarding the relationship between stable isotopes in meteoric waters and climatic parameters is dealing with model approaches based on physical and meteorological processes. These models take into account the complex dependences of the (isotopic) composition of atmospheric vapour upon environmental conditions, such as the transport pathways and the source region conditions. On the other hand due to their wide scale such global circulation models (GCM) are consequently neglecting the influences on the final isotope concentration coming from the location of the precipitation event itself. To cope with that new models have been recently developed mainly based on the local climatic conditions (Liebminger et al., 2006b). Moreover it has been shown that the spatial isotopic variability especially in alpine regions is to a large extent due to meteorological conditions prevailing at the sampling site (Liebminger et al., 2006a).

Stable isotopes provide a seasonal meteoric signal in temperate, continental systems (Clark and Fritz, 1997) with amplitudes that become more and more attenuated in the groundwater as the mean residence time (MRT) is increasing which therefore decreases the possibility to obtain climatic information from groundwater samples. Temporal changes in the conditions affecting the $\delta^{18} \mathrm{O}$ of precipitation can therefore only be expected to be seen in groundwater of shorter MRTs. The attenuation of precipitation pattern by the underlying catchment can be used to evaluate the MRT using

Published by Copernicus GmbH on behalf of the European Geosciences Union. 

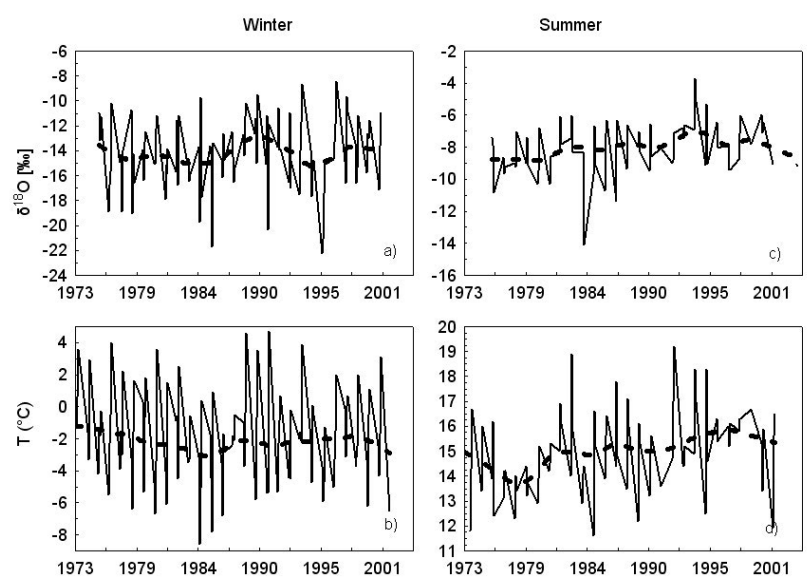

Fig. 1. Time series of temperature measured at Wildalpen and mean $\delta^{18} \mathrm{O}$ values of precipitation sampled at Wildalpen the recharge area for Vienna drinking water. (a) Average $\delta^{18} \mathrm{O}$ values of precipitation for winter months Dec. to March; (b) Average air temperature data for winter months December to March; (c) Average $\delta^{18} \mathrm{O}$ values of precipitation for summer months Jun. to Aug.; (d) Average air temperature data for summer months June to August; For all plots low pass filters are applied (dashed lines).

lumped parameter models assuming that the isotopic attenuation reflects the MRT of transport from recharge through the entire flow system. These models are incorporating the variation of the stable isotopes in precipitation as input function while the response function is obtained from groundwater data. (Maloszewski and Zuber, 1996). Using monthly $\delta^{18} \mathrm{O}$ values from precipitation samples an input function can be calculated according to Maloszweski and Zuber (1996) defined as follows:

$\delta_{\text {in }}(t)=\bar{\delta}+\left[\alpha_{i} P_{i}\left(\delta_{i}-\bar{\delta}\right)\right] /\left(\sum_{i=1}^{n} \alpha_{i} P_{i} / n\right)$

where $\bar{\delta}$ is the mean input which must be equal to the mean output of monthly $\delta^{18} \mathrm{O}$ values and $n$ is the number of months for which the observations are available, $P_{i}$ is the amount of monthly precipitation, $\delta_{i}$ the isotope composition and $\alpha_{i}$ is the recharge factor which is representative for the amount of recharge in the sense that $\alpha=0$ means that no recharge takes place while $\alpha=1$ indicates that all water is recharged.

\section{Methods}

The precipitation is collected on a daily basis in ombrometers $\left(500 \mathrm{~cm}^{2}\right)$ and mixed to monthly samples. Samples for this study were taken between 1961 and 2003. Analyses of oxygen-18 have been made by the isotope laboratories of Austrian Research Centers Seibersdorf (formerly Arsenal research). All together more than 16000 samples were collected during this period. Climate data for this period were provided by Central Institute for Meteorology and Geodynamics, Vienna ${ }^{1}$.

\section{Results and discussion}

In the following the results of an analysis of an unique dataset of almost 30 years of monthly Vienna drinking water samples are presented together with temporal isotopic precipitation data of the corresponding recharge area located in the Austrian Alps (Wildalpen). The temperature data (corresponding to $\delta^{18} \mathrm{O}$ data of precipitation sampled at Wildalpen for summer and winter months respectively) explains $27 \%\left(\mathrm{r}^{2}\right.$ for Summer; $\mathrm{p}=0.006$ ) to $32 \%$ ( $\mathrm{r}^{2}$ for Winter; $\mathrm{p}=0.003$ ) of the variance in the $\delta^{18} \mathrm{O}$ pattern. While there is a significant peak in $1989 / 90$ present within the winter $\delta^{18} \mathrm{O}$ data (Fig. 1a) which is also slightly visible in the winter temperature data (Fig. 1b) the summer month do not reflect the same trends, neither the temperature data nor the $\delta^{18} \mathrm{O}$ pattern (Figs. 1c, d).

The $\delta^{18} \mathrm{O}$ fluctuations of the Wildalpen precipitation correlate to a large extent $\left(\mathrm{r}^{2}=34 \% ; \mathrm{p}=0.002\right)$ with those of the North Atlantic Oscillation (NAO) index, especially for the most extreme values during years 1989/90 and 1996 (Fig. 2a). The NAO has strong impacts on the mean wind speed and direction over the Atlantic and the heat and moisture transport between the North Atlantic region and surrounding continents, especially Europe (Hurrel et al., 2003). Since the NAO is particularly dominant in winter, average values of the December to March period are shown in all the time series of Figs. 2a-c. The ratio of snow to total precipitation $(\mathrm{S} / \mathrm{P})$ is a hydrologic indicator that like the NAO is sensitive to climate variability and can be used to detect and monitor hydrologic responses to climatic change (Huntington et al., 2004). Changes in S/P ratio over time could influence the magnitude and timing of spring runoff and recession to summer base flow. While the climate information within the NAO index is primarily determined at the source of the precipitation (Atlantic Ocean) the S/P ratio, although also mainly based on temperature changes, is potentially influencing the final composition of the precipitation due to non-equilibrium fractionation taking place at the location of the precipitation event itself. The formation of snow as well as sub cloud evaporation processes are both considered to be kinetic processes shifting the final concentration of stable isotopes in precipitation to opposite directions (Liebminger et al., 2006a). Especially the non-equilibrium fractionation during sub cloud evaporation processes of the falling rain drops plays a key role in governing higher $\delta^{18} \mathrm{O}$ values. Relative humidity which is mainly responsible for sub cloud evaporation is consequently of increased importance. Liebminger et al. $(2006 \mathrm{a}, \mathrm{b})$ showed that this is especially true at inter

\footnotetext{
${ }^{1}$ CD-ROM: Klimadaten von Österreich 1971-2000, Central Institute for Meteorology and Geodynamics, Vienna ZAMG 2002, (Auer et al., 2007)
} 
mountain valley stations where air masses arrive due to surrounding mountains at a high level above the ground and at large basins where convective movement of clouds due to higher temperatures is prevailing. On the other hand, at locations in front of orographic barriers enhanced precipitation amounts are occurring which leads to a faster saturation of the ambient air during a precipitation event, thus limiting the effect of evaporation on the falling rain drop.

As shown in Fig. $2 b$ the $\mathrm{S} / \mathrm{P}$ ratio is nearly in anti phase to the $\delta^{18} \mathrm{O}$ pattern indicating that higher $\delta^{18} \mathrm{O}$ values are prevailing when there is more rain among the precipitation falling in the winter months $\left(r^{2}=29 \% ; p=0.005\right)$. Since the $\mathrm{S} / \mathrm{P}$ - ratio is not independent of temperature the partial correlation coefficient

$$
\begin{aligned}
& r_{18 O_{-} S P . T}=\frac{r_{18 O_{-} S P}-r_{S P_{-} T} \cdot r_{18 O_{-} T}}{\sqrt{\left(1-r_{S P_{-} T}^{2}\right) \cdot\left(1-r_{18 O_{-} T}^{2}\right)}} \\
& =\frac{-0.50-(-0.22) .0 .59}{\sqrt{\left(1-(-0.22)^{2}\right) \cdot\left(1-0.59^{2}\right)}}
\end{aligned}
$$

for $\mathrm{S} / \mathrm{P}$ - ratio and $\delta^{18} \mathrm{O}$ partialized by temperature (Eq. 2) has been calculated in order to evaluate whether the S/P ratio to $\delta^{18} \mathrm{O}$ correlation can be traced back on the influence of temperature on the $\mathrm{S} / \mathrm{P}$ - ratio or if there is an additional information in the $\mathrm{S} / \mathrm{P}$ - data.

Since the absolute value of the partial correlation coefficient $r_{18 O_{-} S P . T}(-0.46)$ is only a little smaller than that of the unpartialized correlation $(-0.50)$ there is no evidence that the correlation of $\mathrm{S} / \mathrm{P}$ - ratio with $\delta^{18} \mathrm{O}$ in precipitation is only by virtue of its association with temperature. In order to prove the incremental validity of the $\mathrm{S} / \mathrm{P}$ - ratio factor the multiple correlation of $\mathrm{S} / \mathrm{P}-$ ratio and temperature with $\delta^{18} \mathrm{O}$ has been calculated according to

$$
R_{18 O, S P_{-} T}=\sqrt{\frac{r_{18 O_{-} T}^{2}+r_{18 O_{-} S P}^{2}-2 . r_{T_{-} S P} \cdot r_{18 O_{-} T} \cdot r_{18 O . S P}}{1-r_{T_{-} S P}^{2}}}
$$

The result of 0.70 for $R_{18 O, S P_{-} T}$ in comparison with 0.59 for $r_{18 O_{-} T}$ clearly points out that it is of interest to make use of the information within the S/P - ratio data for isotopic investigations.

Besides the S/P - ratio also relative humidity is in antiphase with $\delta^{18} \mathrm{O}$ in winter precipitation of Wildalpen (Fig. 2c; $\mathrm{r}^{2}=25 \% ; \mathrm{p}=0.010$ ). Considering a lower relative humidity at these winter days with rain $\delta^{18} \mathrm{O}$ values are definitely more influenced by sub cloud evaporation than at days with snowfall and higher relative humidity prevailing. The assumption that a low relative humidity corresponds to higher amounts of rain within the winter precipitation events nicely fits to the observation of sub- cloud evaporation being relevant at days with rain and lower relative humidity, since evaporation of falling snow flakes due to the low molecular diffusion rates in ice can be neglected (Siegenthaler and Oeschger, 1980) as well as with high relative humidity prevailing. In order to provide a consistent picture on the con-
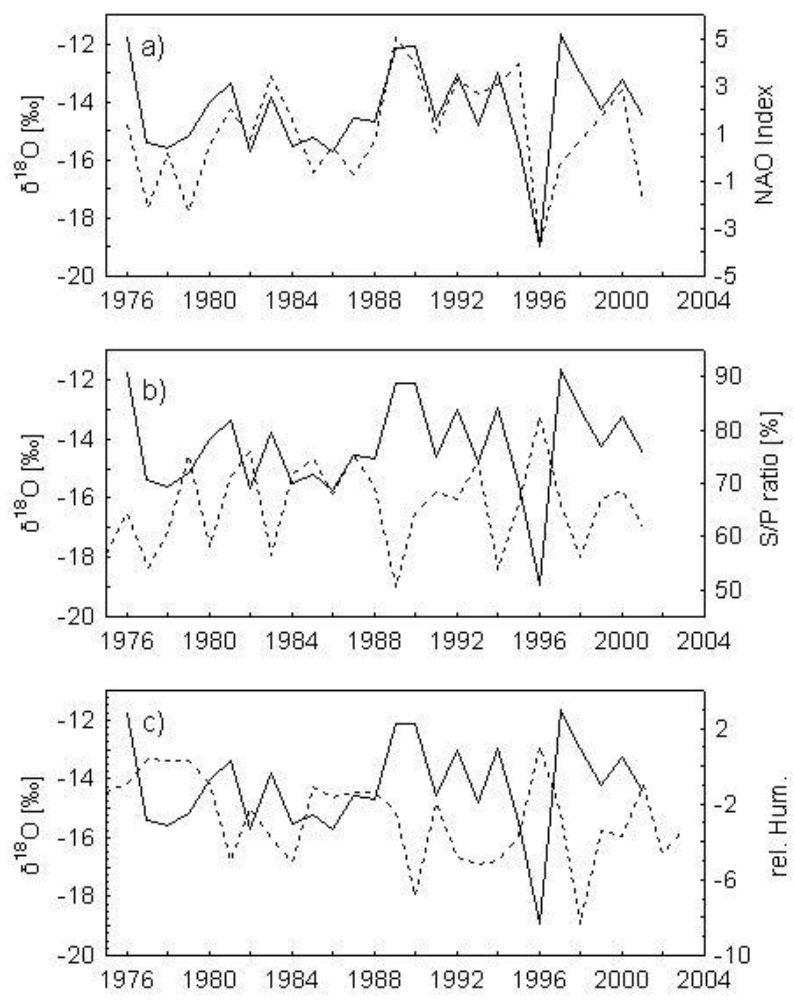

Fig. 2. Comparison time series for $\delta^{18} \mathrm{O}$ values of precipitation sampled at Wildalpen (full lines) together with climate time series (dashed lines) averaged for winter months December to March (a) Comparison with NAO Index; (b) Comparison with snow to precipitation ratio (S/P); (c) Comparison with relative humidity calculated as a relative deviation from the long term mean (Schöner, 2004).

tribution of the different factors to the total variance, an analysis of variance (ANOVA) was carried out. Although some information within the dataset was lost because of conversion of the factors into categorical data (5 factor levels each; Table 1) the result of the ANOVA confirms that a significant part of the variation of the $\delta^{18} \mathrm{O}$ data is explained by all the single factors described above. While almost a third of the total sum of squares is based on temperature data, $24 \%, 21 \%$ and $17 \%$ are based on relative humidity, S/P ratio and NAO index respectively, altogether on a significant $\mathrm{p}$ - level below 0.05 . Figure $3 \mathrm{a}$ clearly shows that the $\delta^{18} \mathrm{O}$ pattern of the precipitation time series of Fig. 1 and Fig. 2 marked by a continuous increase of $\delta^{18} \mathrm{O}$ in the 1980ies followed by an opposite trend from 1990 to 1996 is also present within Vienna drinking water samples. Since recharge is not a constant process over the whole year, i.e. there is less recharge occurring during seasons of warmer temperatures and stronger plant growth due to enhanced evapotranspiration, it is essential not to use the plain precipitation data from the recharge area for comparison but to calculate an input function including an 
Table 1. ANOVA table for $\delta^{18} \mathrm{O}$ in precipitation sampled at Wildalpen based on the factors NAO - index, relative humidity RH, Snow to precipitation ratio S/P and temperature T. ANOVA calculation based on a general linear model with sigma limitation and type VI sums of squares.

\begin{tabular}{lllllll}
\hline & DF & SS & $\%$ & F & p & levels \\
\hline NAO & 4 & 1156.592 & 17.2 & 6.36519 & 0.008 & $<-2 ;-2-0 ; 0-1 ; 1-2 ;>2$ \\
RH & 4 & 1580.762 & 23.5 & 8.69956 & 0.003 & $50-60 ; 60-65 ; 65-70 ; 70-75 ;>75$ \\
S/P & 4 & 1385.376 & 20.6 & 7.62427 & 0.004 & $<-5 ;-5--3 ;-3--2 ;-2--1 ;>-1$ \\
T & 4 & 2143.509 & 31.9 & 11.79658 & 0.001 & $<-3 ;-3--2 ;-2--1 ;-1-0 ;>0$ \\
Error & 10 & 454.265 & 6.8 & & & \\
Total & & 6720.504 & 100.0 & & & \\
\hline
\end{tabular}
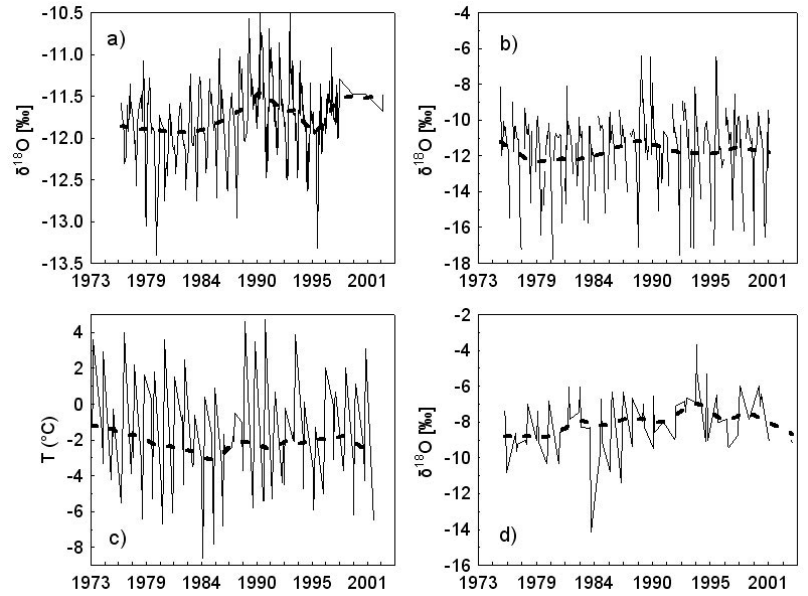

Fig. 3. Time series of Vienna drinking Water and input factors at the recharge area. (a) Monthly mean $\delta^{18} \mathrm{O}$ values of Vienna drinking water (b) Input function calculated from monthly mean $\delta^{18} \mathrm{O}$ values of precipitation sampled at Wildalpen the recharge area for Vienna drinking Water; (c) Average air temperature data for winter months Dec. to Mar. measured at Wildalpen; (d) Average $\delta^{18} \mathrm{O}$ values of precipitation for summer months June to August sampled at Wildalpen; For all plots low pass filters are applied (dashed lines).

appropriate recharge factor for this area. Figure $3 b$ shows the input function for Wildalpen, the concerned recharge area of the Vienna drinking water calculated according to Maloszewski and Zuber (1996) applying a periodical fit for the recharge factor (McGuire et al., 2002):

$\alpha_{i}=0.9 \cos ^{4}(\omega t+\Phi)+0.07$

$\Phi$ is the phase lag in days between precipitation and recharge, $t$ is the calendar time and $\omega$ the angular frequency. Values for $\Phi$ and $\omega$ have been chosen to be 141 and $\pi / 365$ respectively. The suggested periodical fit for the recharge factor gives a more realistic adjustment compared to a solely summer/winter recharge as proposed by Grabczak et al. (1984) which would not account for the variations in evapotranspiration and water availability. The calculation of the input function shows that the typical pattern of the groundwater (peak in the beginning 1990ies) is reflected also in the precipitation input when weighted according to higher impact of winter precipitation. An output (i.e. mean residence time MRT) has not been calculated since it is hard to apply a model for the pathways of drinking water! The above described observation again is supporting the assumption that the colder months are mainly responsible for the typical $\delta^{18} \mathrm{O}$ pattern observed in the Vienna drinking water as well as in Wildalpen precipitation (see above). This conclusion is especially important because if the data set would be analyzed according to the concept of groundwater being generally reflected by annual mean precipitation (cf. Clark and Fritz, 1997) the information about climate impacts as pointed out will be lost.

Figures $4 \mathrm{a}$ and $\mathrm{b}$ further prove strong evidence of local influences on the $\delta^{18} \mathrm{O}$ variation as they show two different situations with the one issue in common, that the observed trends can not be explained by temperature alone. The first situation is characterized by two stations (Innsbruck and Patscherkofel) located very close to each other but showing quite different trends for $\delta^{18} \mathrm{O}$ (Fig. 4a). From Fig. 5 it can be seen that this difference can not be attributed to temperature because there is almost no difference in the temperature trends of Innsbruck and Patscherkofel. Whereas the slope of $\delta^{18} \mathrm{O}$ for Patscherkofel is almost the same as for temperature, this is not the case for the valley station Innsbruck. In general almost no difference regarding the temperature trends between Austrian mountain and valley stations could have been observed (Auer et al., 2001). Since 1850 there has been an increase in annual mean temperature of $\sim 1.8^{\circ} \mathrm{C}$ at high as well as at low elevations. Another important result which can also be seen from the trends in Fig. 4a is that the $\delta^{18} \mathrm{O}$ difference between the valley station Innsbruck $(577 \mathrm{~m}$ a.s.1.) and the mountain station Patscherkofel (2245 $\mathrm{m}$ a.s.l.) has increased significantly over the last 30 years.

The second situation is characterized by two sample stations (Kufstein and Weyregg) located in the same landscape profile (Northern hill slopes of the Alps, both at $\sim 500 \mathrm{~m}$ a.s.1.) but in more than $150 \mathrm{~km}$ distance. Despite 

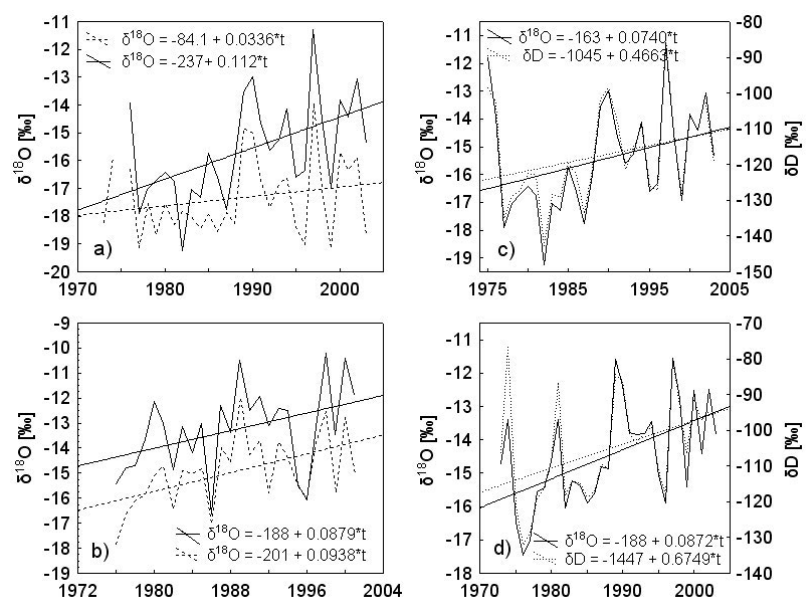

Fig. 4. Comparison time series for different locations in $\delta^{18} \mathrm{O}$ and $\delta$ D. (a) $\delta^{18} \mathrm{O}$ values of precipitation sampled at Innsbruck (full line) and Patscherkofel (dashed line). The mountain sample station Patscherkofel at an altitude of $2245 \mathrm{~m}$ a.s.l. is located within $10 \mathrm{~km}$ of geographic proximity to the city of Innsbruck $(577 \mathrm{~m}$ a.s.l) in the deep inner alpine "Inn-valley". (b) $\delta^{18} \mathrm{O}$ values of precipitation sampled at Weyregg (full line) and Kufstein (dashed line). Both sample stations are located on the northern border of the Alps but at a lateral distance of more than $150 \mathrm{~km}$. (c) $\delta^{18} \mathrm{O}$ (full line) and $\delta \mathrm{D}$ (dotted line) trends for Innsbruck; (d) $\delta^{18} \mathrm{O}$ (full line) and $\delta \mathrm{D}$ (dotted line) trends for Kufstein. All time series represent average values for winter season.

the large distance the $\delta^{18} \mathrm{O}$ trends for these two locations are quite similar. The remarkable $\delta^{18} \mathrm{O}$ offset of almost $2 \%$ o between the two locations (Fig. 4b) can again not be explained by temperature because at both locations there are almost the same temperatures prevailing (cf. Liebminger et al., 2006a). Together with the trends of the $\delta^{18} \mathrm{O} / \delta \mathrm{D}$ - trends both described situations can be interpreted as indicators for increasing importance of sub - cloud evaporation which can be explained by a decrease in relative humidity. Formayer et al. (2001) showed that besides the well known increase of temperature there is only one parameter showing a very significant trend in Austria within the last 30 years: the decrease of relative humidity!

For both examples above the overall year to year $\delta^{18} \mathrm{O}$ variation remains quite similar making the essential part of the information which does not come directly from temperature quite hard to extract. In order to reveal this hidden part it is necessary to compare the $\delta^{18} \mathrm{O}$ data of interest to a different data set with lower or none dependence upon sub cloud evaporation. This is the case for the above mentioned valley/mountain example, because the influence of sub cloud evaporation at the summit of Patscherkofel (2245 $\mathrm{m}$ a.s.l.) is negligible. Another possibility is to compare $\delta^{18} \mathrm{O}$ with $\delta \mathrm{D}$ since Deuterium will be enriched by a lesser extent during evaporation processes. Figures $4 \mathrm{c}$ and d clearly show a decrease of the relative difference between $\delta^{18} \mathrm{O}$ and $\delta \mathrm{D}$ over the last decades for sample stations Innsbruck and Kufstein

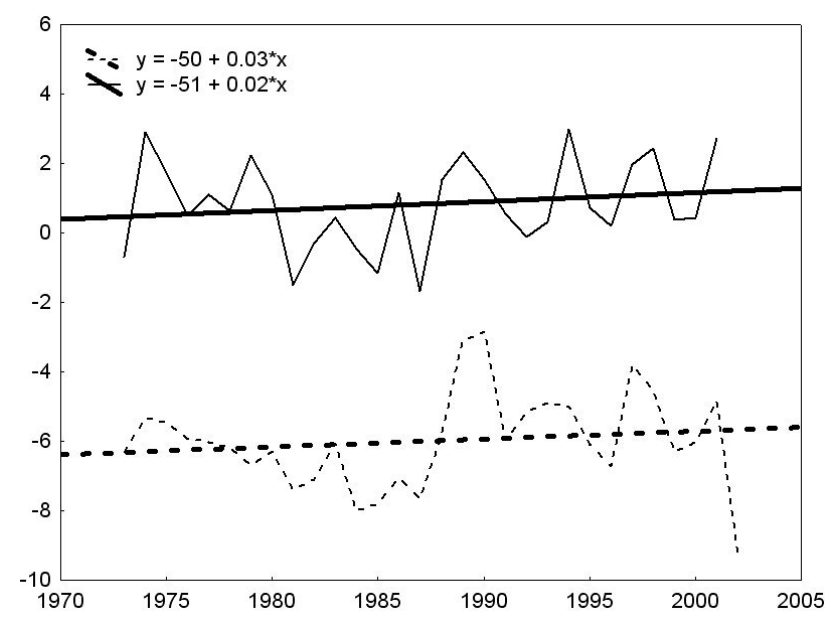

Fig. 5. Temperature trends for Innsbruck (full lines) and Patscherkofel (dashed lines). Temperature data represent mean values for winter months December to March.

manifested in a steeper slope of $\delta^{18} \mathrm{O}$ in comparison to $\delta \mathrm{D}$ clearly indicating that sub cloud evaporation has become of increased importance during the last 30 years.

The above described effect is either enhanced or lowered by the amount of precipitation which is occurring during the events as has been described by Dansgaard (1964) as the amount effect especially for tropical areas. Drizzle or very small rain drops are relatively more affected by sub cloud evaporation as heavy rain during storm events. Therefore smaller precipitation amounts have to be expected at times with higher $\delta^{18} \mathrm{O}$ values and vice versa which is confirmed by Fig. 6a showing an example of Vienna precipitation records (which are averaged for winter months December to March). From the local meteoric water lines (LMWL) drawn for this location for the time periods before 1989 (Fig. 6c) and after 1989 (Fig. 6d) it can be seen that the slope of the later values is significantly lower than that of the earlier values which is always a strong indicator of enhanced evaporation effects (Clark and Fritz, 1997).

\section{Conclusions}

We summarize that the isotopic composition of meteoric water is not only reflecting the influence of temperature but also that of other local meteorological parameters which will definitely be of considerable interest for (paleo)climatic applications! Especially we show for the first time that younger groundwater due to special recharge conditions is a potential reservoir of climate information bearing just more than temperature. Although especially alpine regions are able to deliver a lot of different and representative sample sites future studies covering larger geographical areas will be necessary in order to get more input on the extent of the obvious and hidden information within the stable isotopes variation in precipitation and groundwater. 

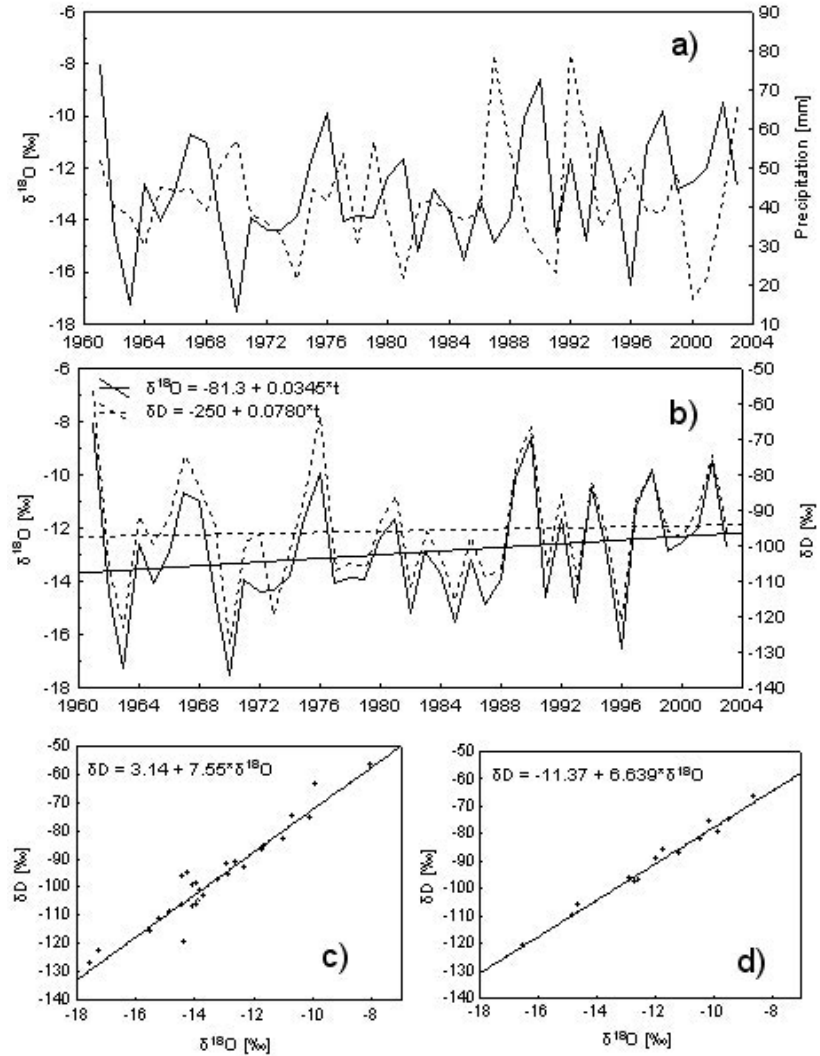

Fig. 6. Influences on stable isotopes in Vienna precipitation. (a) Comparison time plot for $\delta^{18} \mathrm{O}$ values of precipitation (full line) and amount of precipitation (dashed line) sampled at Vienna Hohe Warte; (b) $\delta^{18} \mathrm{O}$ (full line) and $\delta \mathrm{D}$ (dashed line) trends for Vienna; (c) Plot of the Vienna local meteoric water line for $\delta^{18} \mathrm{O}$ and $\delta \mathrm{D}$ representing the winter months of the years 1961 to 1989; (d) Plot of the Vienna local meteoric water line for $\delta^{18} \mathrm{O}$ and $\delta \mathrm{D}$ representing the winter months of the years 1989 to 2003 .

Acknowledgements. We thank the Umweltbundesamt (Vienna) which is in charge of the majority of the sampling stations. We are further grateful to the people of the, Bundesministerium für Land- und Forstwirtschaft, Umwelt und Wasserwirtschaft, Abteilung VII/3 - Wasserhaushalt (Hydrographisches Zentralbüro“ for providing the monthly mean temperature data (status: 05/2004) and to R. Böhm from the Central Institute for Meteorology and Geodynamics, Vienna for his valuable input on climatology.

Edited by: K. Roth

\section{References}

Auer, I., Böhm, R., and Schöner, W.: Austrian long-term Climate 1767-2000, Österr. Beiträge zu Meteorologie und Geophysik, Heft 25. Central Institute for Meteorology and Geodynamics, Vienna, 2001.

Auer, I., Böhm, R., Jurkovic, A., Lipa, W., Orlik, A., Potzmann, R., Schner, W., Ungersböck, M., Matulla, C., Briffa, K., Jones, P.,
Efthymiadis, D., Bruntetti, M., Nanni, T., Maugeri, M., Mercalli, L., Mestre, O., Moisselin, J. M., Begert, M., Mllerwestermeier, G., Kveton, V., Bochnicek, O., Stastny, P., Lapin, M., Szalai, S., Szentimrey, T., Cegnar, T., Dolinar, M., Gajic-Capka, M., Zaninovic, K., Majstorovic, Z., Nieplov, E.: HISTALP - Historical Instrumental Climatological Surface Time Series of the Greater Alpine Region 1760-2003, Intern. J. Climat., 27(1), 17 46, 2007.

Clark, I. and Fritz, P.: Environmental Isotopes in Hydrogeology, Lewis Publishers, New York, pp. 328, 1997.

Dansgaard, W.: Stable isotopes in precipitation, Tellus, 16, 436468, 1964

Edwards, T. W. D. and Wolfe, B. B.: Influence of Changing Atmospheric Circulation on Precipitation $\delta^{18} \mathrm{O}$ - Temperature Relations in Canada during the Holocene, Quarterny Research, 46, 211-218, 1996.

Formayer, H., Eitzinger, S., Nefzger, H., Simic, S., KrompKolb, H. Auswirkungen einer Klimaveränderung in Österreich: Was aus bisherigen Untersuchungen ableitbar ist, Report (Institut für Meteorologie und Physik Universität für Bodenkultur); http://www.accc.gv.at/pdf/global2000.pdf, 2001.

Grabczak, J., Maloszewski, P., Rozanski, K., and Zuber, A.: Estimation of the tritium input function with the aid of stable isotopes, Catena, 11, 105-144, 1984.

Huntington, T. G., Hodgkins, G. A., Keim, B. D., and Dudley, R. W.: Changes in the Proportion of Precipitation Occurring as Snow in New England (1949-2000), J. Climate, 17, 2626-2636, 2004.

Hurrell, J. W., Kushnir, Y., Ottersen, G., and Visbeck, M.: An Overview of the North Atlantic Oscillation, in: The North Atlantic Oscillation: climatic signifcance and environmental impact, edited by: Hurrell, J. W., Kushnir, Y., Ottersen, G., and Visbeck, M., Geophys. Monograph, 134, 1-35, 2003.

Jouzel, J., Koster, R. D., Hoffmann, G., and Armengaud, A.: Model evaluations of the water isotope-climate relationships used in reconstructing paleotemperatures, Proc. Int. Symp. on Isotope Techniques in the Study of Environmental Change. Proceedings of a Symposium, Vienna, IAEA-SM 349/34P, IAEA-Keynote address, 485-502, 1997.

Liebminger, A., Haberhauer, G., Papesch, W., and Heiss G.: Correlation of the isotopic Composition in Precipitation with local Conditions in alpine Regions, J. Geophys. Res., 11, D05104, doi:10.1029/2005JD006258, 2006a.

Liebminger, A., Haberhauer, Varmuza, K. G., Papesch, W., and Heiss, G.: Modeling the Oxygen 18 Concentration in Precipitation with Ambient Climatic and Geographic Parameters, Geophys. Res. Lett., 33, L05808, doi:10.1029/2005GL025049, 2006b.

Maloszewski, P. and Zuber, A.: Lumped Parameter Models for the Interpretation of Environmental Tracer Data, Manual on Mathematical Models in Isotope Hydrology. International Atomic Energy Agency, Vienna, Austria, 9-58, 1996.

McGuire, K. J., DeWalle, D. R., and Gburek, W. J.: Evaluation of mean residence time in subsurface waters using oxygen-18 fluctuations during drought conditions in the mid-Appalachians, J. Hydrol., 261, 132-149, 2002.

Noone, D. and Simmonds, I.: Associations between $\delta^{18} \mathrm{O}$ of Water and Climate Parameters in a Simulation of Atmospheric Circulation for 1979-95, J. Climate, 15, 3150-3169, 2002. 
Schöner, W.: The 2004-08 release of the HISTALP precipitation dataset in grid mode 1, Internal project working paper of ECproject ALP-IMP, Available on demand via the project website http://www.zamg.ac.at/ALP-IMP, 2004.
Siegenthaler, U. and Oeschger, H.: Correlation of ${ }^{18} \mathrm{O}$ in precipitation with temperature and altitude, Nature, 285, 314-317, 1980. 